\title{
REPRESENTAC̣ÕES SOCIAIS DE ESTUDANTES DE BIOLOGIA SOBRE AS FUTURAS ATIVIDADES PROFISSIONAIS
}

\author{
FÁBIO LUIS KRÜTZMANN ${ }^{1 *}$ \\ https://orcid.org/0000-0003-0408-0610 \\ LUIZ CALDEIRA BRANT DE TOLENTINO NETO ${ }^{* *}$ \\ https://orcid.org/0000-0001-6170-1722
}

RESUMO: O presente artigo investiga as Representações Sociais, teoria proposta por Serge Moscovici, de 190 estudantes de Ciências Biológicas da Universidade Federal de Santa Maria entre os anos de 2016 e 2018 sobre as futuras profissões: professor e biólogo. Por meio de questionários obtivemos informações sobre o perfil dos estudantes deste curso, assim como suas representações das atividades profissionais. Reunimos 332 palavras diferentes que ajudam a caracterizar a identidade profissional dos acadêmicos a partir dos termos indutores "professor é" e "biólogo é". Ao serem questionados sobre biólogo as respostas orbitam em torno da palavra pesquisador, curioso, amor e importante. Enquanto as respostas para professor centraram-se em educador, ensinar e essencial. Os resultados encontrados contribuem com estudos de formação de professores/biólogos e com reformas e adaptações curriculares dos cursos de Ciências Biológicas. Palavras-chave: Ciências Biológicas. Formação de Professores. Identidade Profissional. Representações Sociais.

\section{REPRESENTACIONES SOCIALES DE ESTUDIANTES DE BIOLOGÍA ACERCA DE LAS FUTURAS ACTIVIDADES PROFESIONALES}

RESUMEN: Este artículo investiga las Representaciones Sociales, teoría propuesta por Serge Moscovici, de 190 estudiantes de Ciencias Biológicas de la Universidad Federal de Santa María entre los años de 2016 y 2018 acerca de las futuras profesiones: profesor y biólogo. Por medio de cuestionarios, obtuvimos informaciones acerca del perfil de los estudiantes de esta carrera, así como sus representaciones de las actividades profesionales.

"Licenciado e bacharel em Ciências
Biológicas pela Universidade Federal de
Santa Maria (UFSM). Mestre em Educação
em Ciências pela UFSM. Doutorando no
Programa de Pós-Graduação Educação
em Ciências: química da vida e saúde da
UFSM. Colaborador do grupo Inter-
institucional Desempenho Escolar
e Inclusão Acadêmica - IDEIA.
E-mail: < fa.biologia22@gmail.com>.
'“ Licenciado e bacharel em Ciências
Biológicas pela Universidade
de São Paulo (USP). Mestre e
Doutor em Educação pela (USP).
Professor da Universidade Federal
de Santa Maria (UFSM). Líder do
Grupo Inter-institucional Desempenho
Escolar e Inclusão Acadêmica - IDEIA.
E-mail: < Icaldeira@gmail.com>.

"Licenciado e bacharel em Ciências Santa Maria (UFSM). Mestre em Educação em Ciências pela UFSM. Doutorando no Programa de Pós-Graduação Educacãa stitucional Desempenho Escolar il. $<$ fabiologia22@gmail.com $>$.

cenciado e bacharel em Ciências Biológicas pela Universidade de São Paulo (USP). Mestre Professor da Universidade Federal de Santa Maria (UFSM). Líder do Grupo Inter-institucional Desempenho E-mail:<Icaldeira@gmail.com>.

\footnotetext{
' Universidade Federal de Santa Maria, Santa Maria, RS - Brasil.
} 
Reunimos 332 palabras diferentes que ayudan a caracterizar la identidad profesional de los estudiantes a partir de términos inductores "profesor es" y "biólogo es". Cuando fueron cuestionados sobre biólogos, las respuestas orbitaron alrededor de las palabras investigador, curioso, amor e importante, mientras las respuestas para profesor se centraron en educador, enseñar y esencial. Los resultados hallados contribuyen a los estudios de formación de profesores/biólogos y a reformas y adaptaciones curriculares de la carrera de Ciencias Biológicas.

Palabras clave: Ciencias Biológicas. Formación de Profesores. Identidad Profesional. Representaciones Sociales.

\section{SOCIAL REPRESENTATIONS OF BIOLOGY STUDENTS OF FUTURE PROFESSIONAL ACTIVITIES}

ABSTRACT: The present article investigates the Social Representations, theory proposed by Serge Moscovici, of 190 students of Biological Sciences of the Universidade Federal de Santa Maria between the years of 2016 and 2018 of the future professions: teacher and biologist. Using questionnaires we got the profile of the students of this course, as well as their representations of the professional activities. We have collected 332 different words that help to characterize the academic identity of the students from the inductive terms "teacher is" and "biologist is". When asked about the biologist the answers spin around the words 'researcher', 'curious', 'love', and 'important'. While the answers about teacher focused on 'educator', 'teach' and 'essential'. The results we found contribute to studies of teacher/biologist training and curricular reforms and adaptations of the Biological Sciences courses.

Keywords: Biological Sciences. Teacher Training. Professional Identity. Social Representations. 


\section{CONSIDERACְÕES INICIAIS}

A formação de professores de biologia e de biólogos no Brasil ocorre em cursos de Ciências Biológicas. Historicamente estes cursos têm uma ligação embrionária nas universidades, em vários casos originários de cursos de História Natural, apresentando currículos muito parecidos (BRANDO; CALDEIRA, 2009; MALUCELLI, 2012; OMELCZUK, 2017).

Apenas em 2002 ocorre a publicação das Novas Diretrizes Curriculares Nacionais para a Formação de Docentes para a Educação Básica (BRASIL, 2002), avançando na forma de estruturação das licenciaturas nas universidades, principalmente pela separação e desvinculação dos cursos de bacharelado.

Apesar disto, encontramos ainda hoje cursos de licenciatura extremamente interligados em cursos de bacharelado, mantendo um currículo praticamente idêntico entre as duas formações (MALUCELLI, 2012). Neste nível, o curso de Ciências Biológicas analisado é um exemplo.

Em muitas universidades os conteúdos curriculares da biologia (formação científica) não conseguem fazer relação com os conteúdos pedagógicos (formação pedagógica), favorecendo assim, a dicotomia teórico-prática (TEIXEIRA; OLIVEIRA, 2005). Ainda observamos os cursos de formação de professores com dificuldades de fazer essas relações, como reforça Lelis:

\footnotetext{
No interior do debate sobre a formação de professores, vão sendo aprofundados os problemas crônicos enfrentados pelas instituições formadoras: falta de articulação entre teoria e prática educacional, entre formação geral e formação pedagógica, entre conteúdos e métodos. (LELIS, 2001, p. 49.).
}

Para ser professor, a licenciatura é o percurso obrigatório. Já para o exercício da profissão do biólogo, não existe distinção entre licenciatura ou bacharelado. É requisitada uma dupla habilitação, a primeira com relação ao ensino superior em curso de História Natural ou de Ciências Biológicas. A segunda, a habilitação fornecida pelo Conselho Regional de Biologia (CRBio) (CFBIO, 1979).

A presente pesquisa se insere na área de formação de professores uma vez que mergulha em uma licenciatura em Ciências Biológicas e procura investigar as representações dos estudantes deste curso sobre suas futuras ocupações profissionais: professor e biólogo. Ao olhar para o curso de licenciatura em Ciências Biológicas da Universidade Federal de Santa Maria, visualizamos que este está em simbiose com o curso de bacharelado, existindo um núcleo comum nos primeiros três semestres, em que o aluno ainda não cursa licenciatura nem o bacharelado. A chamada Área Básica de Ingresso funciona como entrada dos estudantes em cursos que irão se separar no decorrer da formação, no caso da UFSM a escolha ocorre no início do quarto semestre. Sendo assim, não poderíamos desconsiderar as concepções dos alunos do bacharelado, pois estes - assim como os licenciados - se formam biólogos.

Há dois Cursos de Ciências Biológicas (CCB) na Universidade Federal de Santa Maria (UFSM): o CCB do campus de Palmeira das Missões/RS apresenta somente a modalidade licenciatura, enquanto em Santa Maria é oferecido ambos. No caso do CCB da UFSM campus Santa Maria, as disciplinas específicas 
(pedagógicas) que diferenciam a licenciatura e que caracterizam a formação de professores, são: as Didáticas, Fundamentos da Educação, Políticas Públicas e os cinco Estágios Supervisionados. Por outro lado, os Trabalhos de Conclusão de Curso (TCC) e a requisição de horas em Disciplinas Complementares de Curso (DCG's) caracterizam o bacharelado na UFSM. O restante do currículo apresenta as mesmas características para ambas as modalidades, dificultando a visualização das diferenças entre elas.

A escolha entre os cursos geralmente ocorre pela atuação profissional, que se caracteriza basicamente como a licenciatura para formar professores e o bacharel para formar pesquisadores das áreas das ciências biológicas.

Estas atuações profissionais aparecem no ideário dos estudantes de distintas formas, tornando-se de nosso interesse mapear essas imagens das futuras profissões. Para melhor compreender como ocorrem as representações do professor e do biólogo nos estudantes, buscamos a teoria das Representações Sociais (RS) proposta por Moscovici no ano de 1961 (MOSCOVICI, 2010).

A teoria das RS foi escolhida como aporte teórico/metodológico desta pesquisa, pois ela ajuda a compreender a mobilidade e estrutura das representações das pessoas e como coletivamente se constroem. As RS são teorias sobre o senso comum, construídas e partilhadas socialmente e com o objetivo de agir e interpretar o real (MOSCOVICI, 2010). Segundo o referido autor, as RS se caracterizam por:

[...] se tornam capazes de influenciar o comportamento do indivíduo participante de uma coletividade. É dessa maneira que elas são criadas, internamente, mentalmente, pois é dessa maneira que o próprio processo coletivo penetra, como o fator determinante, dentro do pensamento individual. Tais representações aparecem, pois, para nós, quase como que objetos materiais, pois eles são o produto de nossas ações e comunicações. (MOSCOVICI, 2010, p. 40).

Para Moscovici (2010) as RS surgem da necessidade de tornar o não familiar em familiar, ou seja, tornar o desconhecido em conhecido, isto ocorre pelos processos de ancoragem e objetificação que segundo o autor:

Ancoragem e objetificação são, pois, maneiras de lidar com a memória. A primeira mantém a memória em movimento e a memória é dirigida para dentro, está sempre colocando e tirando objetos, pessoas e acontecimentos, que ela classifica de acordo com um tipo e os rotula com um nome. A segunda, sendo direcionada para fora (para outros) tira daí conceitos e imagens para juntá-los no mundo exterior, para fazer as coisas conhecidas a partir do que já é conhecido. (MOSCOVICI, 2010, p. 78).

Nos estudos de Abric (1998) as RS se estruturam em núcleo central e elementos periféricos. O núcleo central se caracteriza por ser estável e representar solidamente o significado de uma representação, enquanto os elementos periféricos são fluidos e surgem no cotidiano, fazendo relação com o núcleo central através da ancoragem com a situação concreta.

Pesquisas envolvendo representações sociais e estudantes de graduação, principalmente futuros professores, aparecem em diversos contextos no 
Brasil. Tolentino e Rosso (2014) pesquisaram as RS de estudantes de um curso de licenciatura em Ciências Biológicas sobre professor e biólogo em uma universidade do interior do Paraná. Os resultados evidenciaram diferenças entre as representações de biólogo e professor, o que inspirou o presente trabalho a investigar diferentes cursos e realidades.

O livro “A formação psicossocial do professor” de Galvão e Siveres (2015) reúne diversos trabalhos com a teoria das Representações Sociais na educação e na formação de professores. Demonstra uma variedade de aplicações em metodologias utilizadas em conjunto das RS, ao mesmo tempo em que comprova a flexibilidade das RS para investigar diversas realidades.

As Representações Sociais podem apresentar um campo frutífero para os estudos sobre identidades, como apresentam os autores Deschamps e Moliner (2014), o entrelaçamento entre estas áreas favorece o debate de necessidades e de afirmações de indivíduos e coletivos. As representações identitárias se referem a conhecimentos e crenças que os indivíduos fazem de si mesmos ou de grupos específicos (DESCHAMPS; MOLINER, 2014).

Para Ciampa (2001) a identidade corresponde a um processo dialético de eterno movimento entre diferenças e igualdades, assim afirma que surgem identidades coletivas e individuais, que segundo o autor:

Então, ao estudar um ser humano, deve ficar claro que se está sempre estudando uma formação material determinada, qualquer que seja o corte feito na universalidade das relações recíprocas em que está inserido (o que autoriza, sem ilogicidade, por exemplo, falar tanto em identidade pessoal como em identidade(s) coletiva(s) no âmbito das ciências humanas). (CIAMPA, 2001, p. 150-151).

Através das RS das futuras profissões buscamos identificar traços da identidade profissional coletiva dos estudantes de biologia. A construção da identidade profissional é um processo extenso e complexo, construído socialmente nos espaços de formação e trabalho. Conforme Batista (2004) pode ser a faculdade um espaço de construção coletiva, que dissemina concepções, características, ideias e opiniões. Este processo ocorre de forma não linear, e submetido a influências do contexto histórico e social.

Direcionamos a nossa atenção à formação, pois é na graduação que os estudantes iniciam a constituição de uma identidade profissional. Esta construção ocorre em uma lógica dialética entre indivíduo e coletivo, como descreve Gomes:

Ou seja, a identidade possui simultaneamente uma dimensão individual, isto é, as ideias, concepções e representações que construímos sobre nós mesmos; e uma dimensão coletiva, isto é, os papéis sociais que desempenhamos em cada grupo do qual pertencemos (familiar, profissional, escolar, religioso, etc.). (GOMES, 2008, p. 4).

Dessa forma, o objetivo da pesquisa se concretiza em buscar as Representações Sociais de estudantes do CCB da UFSM (Santa Maria) sobre suas futuras profissões, relacionando-as com a construção de uma identidade profissional. Este objetivo se relaciona com a intenção de contribuir com a área de formação de professores 
e biólogos, repensando os cursos de graduação - licenciatura e bacharelado - e suas necessárias reformas curriculares. Refletir sobre a construção da identidade profissional perpassa o currículo e os objetivos da formação no ensino superior.

\section{PERCURSO METODOLÓGICO}

Utilizamos o questionário como instrumento de pesquisa, pois este apresenta características favoráveis ao interesse da investigação: permite o anonimato dos participantes, apresenta baixo custo e uma padronização dos resultados (CHAER; DINIZ; RIBEIRO, 2011).

Desenvolvemos o questionário em duas partes, com objetivos específicos. A primeira parte com dados pessoais dos alunos buscava identificar algumas características censitárias dos estudantes que iriam participar da pesquisa. Acreditamos ser importante esse olhar, pois identificamos idade, gênero e quantos alunos trabalhadores existem no curso. Essas informações nos ajudam a conhecer o estudante e adquirir um perfil (VASCONCELOS; LIMA, 2008). Também solicitamos para os ingressantes a manifestação de suas intenções de curso entre bacharelado e licenciatura. Já para os concluintes, em qual curso estavam se formando.

A segunda parte consiste em uma associação livre de palavras (ALP), prática muito utilizada em pesquisas com enfoque nas Representações Sociais (ACOSTA et al, 2007), visto que ajuda na investigação sobre a estrutura das representações. Consiste em relacionar palavras a um termo indutor, que no caso da pesquisa foram as frases "professor é" e "biólogo é". A ALP necessita de respostas rápidas e diretas, pois busca recolher informações não racionalizadas, de acordo com Coutinho (2003, p. 68), por ser uma técnica projetiva, busca dimensões latentes das representações.

Cada estudante respondia sobre os dois indutores, escrevendo cinco palavras para cada. Os questionários foram impressos em frente e verso, de forma que $50 \%$ dos questionários começavam com a ALP sobre "professor é" e outros 50\% começavam com "biólogo é”. Isso impediu que as respostas tivessem influência sempre pela mesma frase inicialmente respondida.

Após escrever as palavras, solicitamos que os alunos as enumerassem em ordem de importância, sendo a primeira palavra com maior importância recebendo o número um e a quinta com menor importância o número cinco. A primeira palavra escolhida na classificação de cada aluno foi justificada em uma frase descritiva. Isso nos ajuda a compreender mais profundamente o significado que os estudantes dão sobre biólogo e professor e assim consolidando o entendimento das representações.

A aplicação do questionário foi feita pelo pesquisador em horário que os estudantes estavam em aula, no final ou no início, dependendo da preferência do professor responsável pela disciplina. Apresentamos um Termo de Consentimento Livre e Esclarecido para os alunos e a participação ou não na pesquisa foi opcional, podendo em qualquer momento ocorrer desistência por parte dos alunos participantes. Em média os alunos levaram 20 minutos para responder ao questionário da pesquisa.

O questionário foi aplicado em seis turmas de graduandos em Ciências Biológicas da UFSM. Foram aplicados nos anos de 2016, 2017 e 2018, sempre no início do ano, para uma turma de calouros e uma de formandos. O amplo tamanho da amostra torna-se necessário para a robustez dos dados analisados. 


\section{ANÁLISE DOS DADOS}

Após a aplicação dos questionários realizamos a tabulação dos dados, atribuindo códigos para cada respondente. O código tem a função de facilitar a identificação de cada questionário no banco de dados geral, ao mesmo tempo garantir o anonimato dos participantes quando utilizarmos alguma referência de um questionário em específico. Cada código contém a letra "I" de ingressantes ou "C" de concluinte, seguido dos números "6", "7" ou "8" em referência ao ano da coleta, após a letra "S" de Santa Maria e por último um número aleatório para cada coleta, iniciando no um até o número de alunos em cada turma amostrada. Como exemplo pegamos um aluno ingressante no ano de 2017 em Santa Maria e que foi o primeiro questionário tabulado em sua turma, teria como código I7S1.

A primeira parte do questionário, que apresentava as questões sobre o estudante, como idade, trabalho, gênero, e opção de curso foram analisadas em conjunto com o intuito de compreender melhor quem é o estudante de Ciências Biológicas que participou da pesquisa.

Colaboraram com a pesquisa 190 estudantes, 72 em 2016, 54 em 2017 e 64 em 2018. 127 estudantes se identificaram com o gênero feminino e 63 com o gênero masculino. A idade média destes alunos foi de 22 anos, ingressante com média de 21 anos e concluintes com média de 24 anos. Em relação ao trabalho, apenas 13 estudantes indicaram trabalhar e estudar ao mesmo tempo.

Sobre as intenções de curso, entre os ingressantes a procura pelo bacharelado é maior, 75 alunos, enquanto para a licenciatura, demonstraram interesse apenas 19. Um aluno afirmou querer fazer ambos os cursos e 18 estudantes não sabiam naquele momento qual curso escolheria. Entre os concluintes a licenciatura reuniu nos três anos 39 alunos, enquanto que o bacharelado ficou com 38 . O aumento no número de alunos da licenciatura ocorre por diversos motivos, entre eles, encontramos na produção de Allain, Coutinho e Silva (2013) que alunos se vislumbram com o magistério no decorrer do curso, também relacionando uma maior empregabilidade da carreira docente.

Para a classificação das palavras e análise segundo a teoria das Representações Sociais de forma estrutural (ABRIC, 1998; 2001) levamos em conta o núcleo central das representações, e elementos periféricos que subdividimos em intermediários e periferia. Para isso utilizamos o software OPENEVOC-0.84 para relacionar as frequências e a classificação das palavras evocadas pelos estudantes. A frequência representa quantas vezes a palavra apareceu nos questionários enquanto a classificação deu origem a Ordem Média de Importância (OMI), número gerado da média que cada palavra teve em relação à importância que os alunos atribuíram na ALP. As palavras com menor OMI são as palavras mais importantes, pois estão mais próximas do número de classificação mais importante, o número um. Enquanto as classificações menos relevantes são as médias próximas do número cinco.

Estruturamos os resultados em dois quadros, um com os dados referentes a biólogo e outro para professor. Os quadros apresentam quatro quadrantes, que representam cortes na amostra de palavras com relação a frequência e OMI. A escolha dos cortes ocorreu pelo conhecimento do pesquisador em relação a amostra e dos resultados, correspondendo a uma análise de possíveis estruturações. 
Segundo a teoria estrutural de Abric (1998), a posição do núcleo central (quadrante superior esquerdo) reúne as palavras com maior frequência e menor OMI. Para o autor, o núcleo central apresenta duas funções principais: função de organizar as representações, pois garante a coerência e a estabilidade da representação, e função geradora, pois possibilita a criação e transformação dos significados (ABRIC, 1998).

$\mathrm{O}$ quadrante superior direito reúne os elementos intermediários com maior frequência, porém com baixa importância, são as palavras que repetidamente aparecem ligadas aos núcleos centrais, porém com uma OMI alta, demonstrando menor importância nas representações.

Enquanto o quadrante inferior esquerdo abriga as palavras com baixa frequência e significativa importância, OMI baixa. São termos que se aproximam do núcleo central por sua importância, porém não são muito frequentes.

Já o quadrante inferior direito, reúne os elementos da periferia distante, palavras com baixa frequência e alta OMI, ou seja, pouca importância. Estas palavras funcionam como defesas do núcleo, regulando possíveis mudanças sem comprometer o significado da representação (ABRIC, 1998).

Ao todo foram coletadas 1788 palavras sobre os dois indutores. Para o termo indutor biólogo, encontramos 864 palavras, sendo 184 palavras diferentes entre si, enquanto para professor foram 924 palavras, das quais 234 eram diferentes. As palavras de mesma origem, com diferenças em seus sufixos, foram reunidas em uma única palavra. Por exemplo, as palavras amor e amar, apresentam a mesma origem, então optamos por permanecer com a palavra com maior frequência e igualar às palavras parecidas a ela.

\section{REPRESENTAC̣ÕES SOBRE BIÓLOGO}

A seguir reunimos as palavras referentes ao termo indutor "biólogo é", apenas foram consideradas as palavras com frequência acima de $0.9 \%$ (o equivalente a 7 aparições). No quadro abaixo, encontramos os quatro quadrantes da estruturação das Representações Sociais dos estudantes.

O núcleo central das representações (quadrante superior esquerdo do quadro) consiste em palavras com maior frequência de aparições nos questionários e também palavras classificadas com maior importância pelos estudantes. As palavras que se estabilizaram no núcleo central foram: pesquisador, curioso, amor e importante. Algumas palavras apresentaram OMI maior que outras, como amor e curioso, porém o termo pesquisador teve a maior frequência entre todas as palavras evocadas. 
Quadro 1. Distribuição das representações geral sobre "Biólogo é"

\begin{tabular}{|c|c|c|c|c|c|}
\hline \multicolumn{3}{|c|}{ Frequência $>=2.5 \% / \mathrm{OMI}<2.8$} & \multicolumn{3}{|c|}{ Frequência $>=2.5 \%$ / OMI >= 2.8} \\
\hline $8.68 \%$ & Pesquisador & 2.76 & $4.1 \%$ & Cientista & 2.8 \\
\hline $6.1 \%$ & Curioso & 2.35 & $3.52 \%$ & Conhecimento & 2.8 \\
\hline $4.57 \%$ & Amor & 2.1 & $3.28 \%$ & Responsável & 2.96 \\
\hline $2.7 \%$ & Importante & 2.65 & & & \\
\hline \multicolumn{3}{|c|}{ Frequência $<2.5 \%$ / OMI $<2.8$} & \multicolumn{3}{|c|}{ Frequência $<2.5 \%$ / OMI $>=2.8$} \\
\hline $1.76 \%$ & Preservar & 2.6 & $2.46 \%$ & Dedicado & 3.71 \\
\hline $1.76 \%$ & Profissional & 2.73 & $2.34 \%$ & Natureza & 3.3 \\
\hline $1.64 \%$ & Vida & 2.36 & $2.23 \%$ & Professor & 2.84 \\
\hline $1.52 \%$ & Protetor & 2.77 & $1.76 \%$ & Profissional & 2.73 \\
\hline $1.41 \%$ & Conscientizador & 2 & $1.76 \%$ & Necessário & 2.8 \\
\hline $1.17 \%$ & Comprometimento & 2.7 & $1.76 \%$ & Consciente & 2.93 \\
\hline \multirow[t]{8}{*}{$0.94 \%$} & Respeito & 2.75 & $1.76 \%$ & Desvalorizado & 3.27 \\
\hline & & & $1.41 \%$ & Descobridor & 3.42 \\
\hline & & & $1.29 \%$ & Estudioso & 2.91 \\
\hline & & & $1.17 \%$ & Comprometimento & 2.7 \\
\hline & & & $1.17 \%$ & Questionador & 2.8 \\
\hline & & & $1.17 \%$ & Educador & 2.9 \\
\hline & & & $1.17 \%$ & Essencial & 3.2 \\
\hline & & & $1.06 \%$ & Interessado & 3.44 \\
\hline
\end{tabular}

Fonte: criado pelo autor.

Analisaremos as palavras do núcleo central mais a fundo, iniciando com o termo de maior frequência, pesquisador. O biólogo é referenciado como aquele que realiza pesquisas científicas, sendo uma característica vinculada a profissão. Um aluno justifica a sua escolha da seguinte maneira:

"A pesquisa é sempre presente para o biólogo em todas as áreas de dentro do curso" (C7S20).

Outro estudante traz em sua justificativa a pesquisa como algo central nesta profissão, e ainda a compreensão de licenciados e bacharéis serem biólogos, quando afirma: 
"Eu considerei o biólogo como um pesquisador, pois o biólogo, sendo bacharel ou licenciado esta/deve estar constantemente engajado em pesquisa científica, sempre buscando ampliar conhecimentos da ciência no mundo" (I7S19).

Já a palavra Curioso remete a uma característica pessoal de quem é biólogo, alguns alunos trazem isso nas justificativas:

"para mim, um biólogo principalmente é alguém muito curioso com a vida e o mundo que o cerca" (I6S37).

“o biólogo deve ser curioso porque isso lhe dá combustível para desbravar o mundo e seus mistérios" (I7S24).

A curiosidade nestes casos seria algo vinculado ao biólogo, que tem curiosidade de descobrir e desbravar o mundo. O termo curioso por ter essa característica mais pessoal, é uma representação vinculada ao ser profissional biólogo, juntamente com o termo amor, que também faz parte do núcleo central.

A palavra amor foi o elemento com OMI mais baixo, o que significa que ficou classificada como maior importância entre as palavras evocadas. Esta posição demarca a significação de caráter mais pessoalizado feito pelos estudantes quanto à profissão biólogo. As justificativas a seguir revelam que os estudantes vinculam o amor a diferentes características da profissão, podendo ser a formação, a natureza, a vida ou a própria profissão:

“para ser biólogo é necessário amor a sua formação pois requer grande dedicação” (I6S5).

"ser biólogo é, acima de tudo, amar a natureza a vida e os seres vivos" (I7S5).

"biólogo é amor porque é uma profissão que exige um comprometimento e carinho por parte de quem a executa, principalmente por não darem a devida importância a ela” (C8S12).

Por fim, o elemento importante revela a relevância da profissão na representação destes alunos, considerando o biólogo como o profissional que trabalha para um bem comum, como afirma o estudante C6S10:

"pela amplitude de atividades e serviços que pode prestar tanto em nome da natureza como da sociedade" (C6S10).

Ou como afirma outro estudante, o biólogo é um importante profissional pois pode reverter algumas situações indesejadas:

"pois, diante das barbaridades ambientais que ocorrem precisa-se de um profissional que tente reverter isso" (C7S22).

Como elementos intermediários algumas palavras estão mais fortemente ligadas ao núcleo central, e outras mais distantes. Estão presentes no quadrante 
superior direito, os termos cientista, conbecimento e responsável, palavras que apresentam uma frequência alta, ao mesmo tempo em que sua OMI indica não serem os mais importantes. Isso demonstra que devem fazer ligação com os elementos do núcleo central nas representações.

$\mathrm{O}$ quadrante inferior esquerdo apresentou palavras como: preservar, profissional, vida, protetor, conscientizador... Esse quadrante reúne palavras com uma importância elevada em comparação aos outros termos intermediários, porém sua frequência é baixa, são termos que podem contrastar com o restante dos termos intermediários ou a presença de uma representação diferente na forma de subgrupo (MARQUES, 2016).

Os elementos periféricos (quadrante inferior direito) cumprem com o papel de ancoragem na realidade (ABRIC, 1998), trazem concepções do real que fazem referência ao núcleo central. São palavras que apresentam uma frequência menor, mas existem em maior variabilidade, o que representa uma realidade mais heterogênea de representações, característica de elementos periféricos. Palavras como: interessado, estudioso, ético e educador representam parte desse grande universo dos elementos periféricos.

O elemento periférico professor chamou a atenção. Visualizamos que alguns estudantes entendem que o biólogo também é professor, podendo relacionar a questão da licenciatura com a certificação do CFBio, ou aos professores do ensino superior que podem ser biólogos e não necessariamente ter a licenciatura.

\section{REPRESENTAC̣ÕES PROFESSOR}

Analisaremos os quatro quadrantes das representações de professor, iniciando com o núcleo central até os elementos periféricos. O núcleo central das representações de professor difere agudamente do indutor biólogo, reforçando a distância entre os significados e os sentidos atribuídos para as profissões.

Abaixo apresentamos os quatro quadrantes do quadro de estruturação das RS referente ao termo indutor "professor é". O núcleo central localizado no quadrante superior esquerdo, elementos intermediários no quadrante superior direito e inferior esquerdo e os elementos periféricos, quadrante inferior direito. Foram avaliadas apenas as palavras com frequência acima de $0.9 \%$ (equivalente a 7 aparições), assim como realizado com o primeiro indutor. 
Quadro 2. Distribuição geral das representações para 0 termo indutor "Professor é"

\begin{tabular}{|c|c|c|c|c|c|}
\hline \multicolumn{3}{|c|}{ Frequência $>=2 \% / 0 \mathrm{MI}<2.5$} & \multicolumn{3}{|c|}{ Frequência >= $\%$ / OMI >= 2.5} \\
\hline $5.33 \%$ & Educador & 2.35 & $3.59 \%$ & Conhecimento & 2.79 \\
\hline $2.72 \%$ & Ensinar & 2.24 & $3.48 \%$ & Responsável & 2.94 \\
\hline \multirow[t]{8}{*}{$2.5 \%$} & Essencial & 1.83 & $3.37 \%$ & Dedicado & 2.94 \\
\hline & & & $2.93 \%$ & Paciente & 3 \\
\hline & & & $2.93 \%$ & Desvalorizado & 3.19 \\
\hline & & & $2.5 \%$ & Importante & 2.96 \\
\hline & & & $2.5 \%$ & Amigo & 3.39 \\
\hline & & & $2.07 \%$ & Formador & 2.84 \\
\hline & & & $2.07 \%$ & Exemplo & 3.16 \\
\hline & & & $2.07 \%$ & Pesquisador & 3.26 \\
\hline \multicolumn{3}{|c|}{ Frequência $<2 \% / 0 \mathrm{MI}<2.5$} & \multicolumn{3}{|c|}{ Frequência < 2\% / OMI >= 2.5} \\
\hline $1.74 \%$ & Orientador & 2.44 & $1.96 \%$ & Amor & 3.11 \\
\hline $1.63 \%$ & Base & 2.47 & $1.74 \%$ & Inspiração & 2.88 \\
\hline $1.41 \%$ & Necessário & 2.31 & $1.52 \%$ & Profissional & 3.36 \\
\hline $1.09 \%$ & Futuro & 1.2 & $1.52 \%$ & Mestre & 3.57 \\
\hline \multirow[t]{7}{*}{$1.09 \%$} & Guia & 2.3 & $1.41 \%$ & Aprender & 3.46 \\
\hline & & & $1.41 \%$ & Sabedoria & 3.46 \\
\hline & & & $1.3 \%$ & Trabalhador & 3 \\
\hline & & & $1.09 \%$ & Educação & 3 \\
\hline & & & $0.98 \%$ & Transmissor & 3.11 \\
\hline & & & $0.98 \%$ & Inteligente & 3.33 \\
\hline & & & $0.98 \%$ & Motivador & 3.56 \\
\hline
\end{tabular}

Fonte: criado pelo autor.

Os elementos centrais da representação foram: educador, ensinar e essencial. Os dois primeiros elementos estão fortemente ligados ao sentido que é dado ao professor e sua função na sociedade, em seguida, essencial traz a relevância dada à profissão. O termo educador aparece muitas vezes como sinônimo de professor, mantendo uma relação direta com a função de educar. Ao mesmo tempo em que o professor pode ser considerado um educador por apresentar características distintas do "transmitir conhecimentos", como defendem dois alunos:

“o professor precisa ser um educador e não apenas um transmissor de conhecimento” (C8S2). 
"alguém que tenha a função de ensinar e formar pessoas com senso crítico e conhecimento" (C6S2).

Não podemos ignorar que a imagem de professor tem a influência de anos de escolarização que estes alunos tiveram, e a ideia de transmissor de conhecimento é muito presente nas falas. Algumas justificativas demonstram isso:

"os professores trabalham educando pessoas, ao passar seu conhecimento de modo que construa cidadãos e também o futuro da sociedade" (C6S4).

“o papel principal do professor é transmitir conhecimento" (I6S24).

A palavra ensinar faz parte do núcleo central, dando significado a ação e prática do professor. Ensinar pode ser visto como o objetivo do processo educativo, assim como o papel do professor na educação. Algumas justificativas sobre a escolha da palavra ensinar corroboram com a vinculação do professor ao ato de ensinar:

\footnotetext{
"professor ensina em primeiro lugar" (C6S16).

"o professor deve passar seu conhecimento adiante ensinando" (I8S30)

"é a capacidade de transmitir conhecimento de uma forma adequada" (C6S12).
}

O núcleo central apresenta a palavra essencial com a menor OMI, reforçando sua centralidade, porém sua frequência também é a menor do quadrante. $O$ trabalho do professor aparece como fundamental para os alunos e a sociedade em geral nas seguintes falas:

“o professor é essencial, pois ele desenvolve e ajuda na formação de cada indivíduo” (I6S28).

“o papel do professor é essencial para a formação pessoal e profissional do cidadão” (I7S1).

"cumpre um papel fundamental na sociedade" (C7S5).

Os termos intermediários do quadrante superior direito como: amigo, dedicado, desvalorizado e responsável são bastante comuns nas representações dos estudantes, pois apresentam uma frequência alta, mas ao mesmo tempo uma ODI baixa, são concepções ligadas a realidade do professor e fazem ligação da realidade com o núcleo central. Desvalorizado é uma representação que é muito frequente em professor, e se reduz quase que na metade para biólogo, o que representa a realidade profissional dos docentes. Assim como a palavra pesquisador que faz referência ao professor pesquisador.

O quadrante inferior esquerdo apresenta palavras como: orientador, base, necessário... São termos com frequência baixa, porém sua importância é acentuada. O termo orientador pode fazer referência ao professor de graduação, que orienta 
projetos e pesquisas, novamente podendo existir uma influência do meio universitário nas representações.

Já os elementos periféricos foram: amor, inspiração, profissional, mestre, aprender, sabedoria... A palavra amor surge com pouca expressividade comparada a representações do biólogo, bem como o termo profissional. Os elementos periféricos apresentam características mais individuais dos estudantes, por aparecerem em menor número e com uma menor importância, são termos de maior flexibilidade, podendo ser o início de uma mudança na representação (ABRIC, 1998).

\section{CONSIDERAÇÕES FINAIS}

O perfil dos alunos do CCB que participaram da pesquisa, nos anos de 2016, 2017 e 2018, nos mostra que na maioria são mulheres, em média 22 anos de idade, que ainda não trabalham e que buscam a formação em bacharelado. Cabe ressaltar, aqui, que estas características dos estudantes não foram o foco da presente pesquisa, porém são informações que nos ajudam a compreender a realidade retratada no curso analisado.

Os resultados encontrados, em torno da ALP, nos mostram um núcleo central bem definido em biólogo, com os termos pesquisador, curioso, amor importante, sendo estes elementos que, para os estudantes, dão significado ao ser biólogo. $\mathrm{O}$ restante dos termos, que compõem os elementos intermediários e a periferia, são bastante heterogêneos, fazendo por vezes ligação com pesquisador e trazendo aspectos mais profissionais como: cientista, ético, ambientalista, conscientizador. Outros remetem aspectos pessoais do profissional biólogo, como dedicado e responsável, que por sua vez, são palavras que fazem ligação com os termos mais pessoais do núcleo central, como amor e curioso.

Enquanto para o termo indutor professor o núcleo central foi definido como: educador, ensinar e essencial. Entre os quatro termos, educador tem mais centralidade, e apresenta com mais significância o sentido que os alunos dão a professor. As representações do núcleo central estão fortemente ligadas à atuação profissional, apenas essencial que representa a importância da profissão em si. Os elementos periféricos são heterogêneos e trazem sentidos mais subjetivos, como amigo, responsável, amor e dedicado que representam características pessoais e não profissionais. Entre os elementos periféricos, desvalorizado aparece com alta frequência, isso indica como a realidade profissional do professor já se materializa nas concepções dos professores em formação. Presumimos que isto ocorra principalmente pela desvalorização da carreira docente em nosso país.

A identidade profissional do biólogo, segundo as representações dos estudantes, é direcionada para um pesquisador, curioso e amoroso, é cientista que produz conhecimento, é importante para a sociedade, é dedicado e ético com o que faz. Enquanto o professor é um educador que ensina conhecimentos e é essencial à sociedade, é amigo, dedicado, responsável e exemplo, é também desvalorizado profissionalmente. Os elementos periféricos nos mostram mais características idealizadas de profissão, palavras como: paciente, amor, motivador, defensor e questionador mostram como os alunos projetam características pessoais na atuação do trabalho. 
Gatti (1996) reforça a importância de olharmos para o processo de constituição da identidade docente, mesmo na graduação. Enquanto Pimenta (1996) afirma que a identidade profissional do professor perpassa a significação social da profissão, indo ao encontro da teoria das RS. Com o presente trabalho, constatamos que as representações sociais dos estudantes diferem entre as profissões biólogo e professor, constituindo possíveis identidades profissionais que surgem de um contexto histórico e social, perpassando a formação em nível superior e que se constituirão com maior expressividade ao exercerem as profissões.

Os resultados encontrados vão ao encontro da pesquisa realizada por Tolentino e Rosso (2014) onde também buscava as RS de estudantes de biologia, sobre professor e biólogo. Os núcleos centrais de biólogo e de professor foram muito parecidos, com elementos repetidos e com pesquisador e educador como os termos mais referenciados. Não compreendemos isso como coincidência, as RS são complexas e flexíveis, mas através das pesquisas visualizamos que estudantes de diferentes instituições e em diferentes estados, apresentam representações muito semelhantes sobre suas profissões, mostrando com isso a funcionalidade da teoria das Representações Sociais.

A identidade profissional que os alunos projetam no biólogo é um pouco diferente do que a maior parte dos biólogos em atuação faz, pois não é diretamente o biólogo que faz pesquisa, e sim aquele que desenvolve um trabalho técnico em laboratórios, prefeituras, instituições do Estado como o IBAMA, empresas privadas e realizando licenciamentos ambientais e auditorias. O biólogo que é pesquisador se encontra em maioria nas universidades, mas ele é antes disso um professor.

Enquanto isso, os estudantes de graduação tiveram durante anos vivências com professores no ensino fundamental e médio. Agora estes alunos estão em contato com outro tipo de professor, o professor de ensino superior. Neste sentido, as representações de professor e biólogo se encontram por vezes muito próximas, quando encontramos significativo número de palavras professor referidas a biólogo e pesquisador referindo-se a professor. Desse modo a realidade dos Cursos de Ciências Biológicas, sendo o contexto social analisado, fomenta e corrobora com a constituição destas representações e identidades.

\section{AGRADECIMENTOS E APOIOS}

Agradecemos à CAPES pelo apoio financeiro.

\section{REFERÊNCIAS}

ABRIC, J. C. A abordagem estrutural das representações sociais. In: MOREIRA, A. S. P.; OLIVEIRA, D C. (org.). Estudos interdisciplinares de representação social. Goiânia: AB, 1998.

ABRIC, J. C. O estudo experimental das representações sociais. In: JODELET, D. (org.). As representações sociais. Rio de Janeiro: Ed. Uerj, 2001. 
ACOSTA, S. F. et al. Trabalho docente na ótica de universitários ingressantes. In: Reunião anual da associação nacional de pós-graduação e pesquisa em educação, 30., 2007, Caxambu. Anais... Caxambu: ANPED, 2007.

ALLAIN, L. R.; COUTINHO, F. A.; SILVA, F. A. R e. Translação de interesse: impactos da regulamentação profissional brasileira para biólogos na identidade de professores de biologia. In: Congreso Internacional Sobre Investigación en Didática de las Ciencias, 9., 2013, Girona. Anais... Girona: 2013.

BATISTA, S. H. Aprendizagem, ensino e formação em saúde: das experiências às teorias em construção. In: BATISTA, N.; BATISTA, S.H. (org.). Docência em saúde: temas e experiências. São Paulo: Editora Senac, 2004.

BRANDO, F. R.; CALDEIRA, A. M. A. Investigação sobre a identidade profissional em alunos de Licenciatura em Ciências Biológicas. Ciência e Educação, São Paulo v. 15, n. 1, 2009.

BRASIL. Ministério da Educação. Resolução CNE/CP No 1/2002 - Diretrizes Curriculares Nacionais para a Formação de Professores da Educação Básica, em nível superior, curso de licenciatura, de graduação plena. 2002. Disponível em: <http://portal.mec.gov.br/cne/arquivos/ pdf/CP012002.pdf.> Acesso em: 02 jun. 2017.

CIAMPA, A. C. A estória do severino e a história da severina. São Paulo: Brasiliense. 2001.

CHAER, G; DINIZ, R. R. P; RIBEIRO, E. A. A técnica do questionário na pesquisa educacional. Evidência, Araxá, v. 7, n. 7, p. 251-266, 2011.

COUTINHO, M. P. et al. (org.). Representações sociais: abordagem interdisciplinar. João Pessoa, PB: UFPB, 2003.

GATTI, B, A. Os professores e suas identidades: o desvelamento da heterogeneidade. Cadernos de Pesquisa, São Paulo, n. 98, p. 85-90, 1996.

CFBIO. Lei $\mathbf{n}^{\mathbf{0}} \mathbf{6 . 6 8 4}$, de 3 de setembro de 1979. Regulamenta as profissões de Biólogo e de Biomédico, cria o Conselho Federal e os Conselhos Regionais de Biologia e Biomedicina, e dá outras providências. Legislação do CFBIO. Disponível em: <http://cfbio.gov.br/artigos/LEI-Nº6684DE-3-DE-SETEMBRO-DE-1979>. Acesso em: 24 jun. 2017.

DESCHAMPS, J. C.; MOLINER, P. A identidade em Psicologia Social: Dos processos identitários às representações sociais. Petrópolis: Vozes, 2014.

GALVÃO, A.; SÍVERES, L. (org.), et al. A formação psicossocial do professor: as representações sociais no contexto educacional. Brasília: Liber Livro, 2015.

GOMES, A. A. A construção da identidade profissional do professor: uma análise de egressos do curso de Pedagogia. In: VI Congresso Português de Sociologia, 2008, Lisboa. Anais... Lisboa: Universidade Nova de Lisboa, 2008. v. 6. p. 1-15.

LELIS, I. A. Do Ensino de Conteúdos aos Saberes do Professor: Mudança de Idioma Pedagógico? Educação \& Sociedade, Campinas, SP. n. 74, 2001.

MALUCELLI, V. M. P. B. A prática profissional no curso de Biologia. Estudos de Biologia, v. 34, n. 303 , p. $83,2012$. 
MARQUES, R, R, L. Representações sociais do professor: comunicação, educação e psicologia social. $1^{\mathrm{a}}$ ed. Curitiba: Appris, 2016.

MOSCOVICI, S. Representações Sociais: Investigações em Psicologia Social. Petrópolis, RJ: Vozes, 2010.

OMELCZUK, A. B. Prática como componente curricular - definições legais e sua expressão na formação inicial de professores de ciências e biologia. 2017. 94 p. Dissertação (Mestrado em Educação em Ciências). Universidade Federal de Santa Maria. Santa Maria, 2017.

PIMENTA, S, G. Formação de Professores - Saberes da Docência e Identidade do Professor. Revista da Faculdade de Educação. São Paulo, v. 22, n.2, p, 72 - 89, jul/dez. 1996.

TOLENTINO, P, C.; ROSSO, A. J. As Representações Sociais dos Licenciandos em Ciências Biológicas Sobre o Ser Biólogo e o Ser Professor. Revista Ensaio, v. 16, n.3, p. 15-33, 2014.

TEIXEIRA, L. C. R. S.; OLIVEIRA, A. M. A relação teoria-prática na formação do educador e seu significado para a prática pedagógica do professor de biologia. Revista Ensaio, v. 07, n. 3, p. 220 242, 2005.

VASCONCELOS, S. D. LIMA, K. E. C. O professor de Biologia em formação: reflexão com base no perfil socioeconômico e perspectivas de licenciandos de uma universidade pública. Revista Ciência \& Educação, v. 16, n.2, p. 323-340, 2008.

Submetido em 19/11/2018

Aprovado em 31/05/2019

\section{Contato:}

Fábio Luis Krützmann

Universidade Federal de Santa Maria

CCNE - Prédio $13 \mathrm{~B}$

Avenida Roraima, $\mathrm{n}^{0} 1000$

CEP: $97105-900$ - Santa Maria, RS - Brasil 